\title{
DESENVOLVIMENTO COGNITIVO DO SURDO E AQUISIÇÃO DA LÍNGUA DE SINAIS
}

\section{COGNITIVE DEVELOPMENT IN DEAF PEOPLE AND ACQUISITION OF SIGN LANGUAGE}

\author{
Vanessa da Silva Vargas* \\ Denise Aparecida Moser**
}

\section{Resumo}

Este estudo tem como objetivo entender como ocorre o processo de desenvolvimento linguístico dos surdos na perspectiva de Vygotsky sobre a interligação entre cognição e o contato com a língua e na ótica de Chomsky, que defende a faculdade biológica da linguagem. Para isso, realizou-se uma pesquisa de cunho bibliográfico com o intuito de conhecer mais sobre os circuitos neurais, a capacidade cognitiva, a disposição inata para linguagem e a influência da interação social das pessoas com surdez. Como evidenciam estudos realizados, os surdos não são impossibilitados de aprender. Apenas têm possibilidades distintas e a necessidade de uma exposição adequada a sua língua materna para melhor desenvolvimento de seu potencial linguístico.

Palavras-chave: Surdo. Linguagem. Cognição.

\section{Introdução}

É comum em nossa sociedade atual ver pessoas dispostas a aprender Libras para, supostamente, ajudar os surdos. Aprender essa língua, porém, não deve ter essa finalidade, visto que um surdo não é menos capaz de se desenvolver cognitiva ou linguisticamente do que um ouvinte. Sabendo que os estágios da aquisição da linguagem são explicados ou pela teoria comportamentalista de Skinner (1978), que provém do estímulo e repetição, ou pela teoria gerativa de Chomsky (1971), que propõe uma gramática inata e internalizada, desenvolvida a partir da exposição, ou pela teoria cognitivista de Piaget (1986), ou ainda, pela teoria sociointeracionista de Vygotsky (2000), em que o cognitivo e o social são essenciais para o

\footnotetext{
* Universidade Federal do Pampa (UNIPAMPA), Bagé, Rio Grande do Sul, Brasil. E-mail: vanessavargas.aluno@unipampa.edu.br

** Universidade Federal do Pampa (UNIPAMPA), Bagé, Rio Grande do Sul, Brasil. E-mail: denisemoser@unipampa.edu.br
} 
desenvolvimento linguístico do sujeito, pode-se abordar alguns fatores que demonstram terem os surdos e ouvintes a mesma capacidade cognitiva e linguística.

Assim como as crianças ouvintes têm os estágios pré-linguístico e linguístico, em que apresentam balbucios, palavras e posteriores combinações entre elas, as crianças surdas também apresentam esses estágios. A diferenciação ocorre no ambiente ao qual as crianças estão expostas. Quando uma criança surda, filha de pais ouvintes, é exposta à língua de sinais tardiamente, apenas na idade escolar, por exemplo, ela terá seu desenvolvimento linguístico retardado, uma vez que o input linguístico tem seu ápice aos três anos. Sua dificuldade de aprendizagem está mais ligada ao prejuízo pelo aprendizado linguístico tardio do que às suas capacidades cognitivas.

Nesse contexto, objetiva-se, a partir de pesquisa bibliográfica, entender como ocorre o processo de desenvolvimento linguístico dos surdos na perspectiva de Vygotsky (2000) - a de que há interligação entre cognição e o contato com a língua, pois no significado estão presentes as ligações entre o pensamento e o discurso, na ótica de Chomsky (2015), que defende a faculdade biológica da linguagem. Neste estudo, também são apresentados outros autores, dentre eles, Piaget (1986), Quadros (1997) e Santana (2007), por serem reconhecidamente referências no estudo e discussão acerca da aquisição da linguagem.

\section{A aquisição da linguagem}

Na literatura, em Fonseca (2009), é possível encontrar relatos de pessoas que, mesmo privadas do convívio social por muito tempo, foram capazes de adquirir uma língua de forma tardia, mas permaneceram com algum déficit linguístico, em particular, na sintaxe, o que aponta a existência de um possível período crítico para a linguagem, sobretudo após a infância. É o caso de uma jovem, denominada pelos estudos científicos de Genie, que era carente, vivia isolada, e não foi descoberta até a adolescência. A infância desumana impediu que ela aprendesse um idioma.

O desenvolvimento neuropsicológico e concomitantes sistemas funcionais surgem só quando interagem com um envolvimento apropriado e com adequados requisitos de mediatização. Se uma criança for criada com indivíduos que não falam, nem leem e não a mediatizam cognitiva e simbolicamente, ela nunca aprenderá a falar, a ler ou a pensar criticamente com fluência, ilustrando assim o paradigma das crianças selvagens (por exemplo, caso Genie) (FONSECA, 2009, p. 353). 
A aquisição da língua por parte dos surdos também levanta uma discussão sobre a idade crítica, visto que a maioria dos surdos é filho de pais ouvintes e tem contato e aprendizagem tardios da língua de sinais. Pesquisas como as de Newport (1990), Mayberry e Eichen (1991), Emmorey (1993) e Johnson e Newport (1989) demonstram que, quanto maior a idade, maior o declínio da aprendizagem. Sendo a linguagem uma capacidade biológica, estaria diretamente ligada à maturação cerebral, que faz parte do desenvolvimento humano e tem seu ápice aos 12 anos. Por isso, crianças que não recebem o input linguístico adequado até essa idade perderiam a capacidade de adquirir a linguagem plena, sofrendo prejuízos.

Não há dúvidas sobre a influência do meio e das interações para o desenvolvimento da capacidade linguística, mas a linguagem não é estática. A plasticidade cerebral não se reduz a um limite e há evidências - como na aquisição da língua de sinais em idade adulta, ou ainda, de adultos que aprendem uma segunda língua - que direcionam a um questionamento sobre a rigidez da teoria de que "um cérebro maduro não implica ausência de plasticidade" (SANTANA, 2007, p. 64).

\section{Desenvolvimento cognitivo linguístico do surdo}

Para Vygotsky (2000), a linguagem é mediadora dos processos cognitivos. Se a linguagem é uma capacidade intrínseca de comunicação, é possível que alguém se comunique sem possuir uma língua, mas não sem possuir uma linguagem, qualquer que ela seja. Após o domínio de uma língua, haverá mudanças no cognitivo e no social. Observando essas colocações, compreende-se a razão de o surdo que, mesmo sem adquirir uma língua, não está impedido de pensar, pois continua preservada sua capacidade cognitiva.

Para Goldfeld (2002), a criança surda, sem dominar uma língua, acaba desenvolvendo uma linguagem rudimentar que domina e usa, mas está diretamente ligada ao concreto. Logo, será difícil conversar com ela sobre um assunto abstrato. Um surdo sem língua pode ter dificuldades quanto à organização de seu pensamento:

Da minha infância, as lembranças são estranhas. Um caos na minha cabeça, uma sequência de imagens sem relação umas com as outras, como sequência de um filme, montadas, uma atrás da outra, com longas faixas negras, grandes espaços perdidos. [...] Não há nem primeira nem última lembrança de infância nessa desordem de mim mesma. Há sensações. (LABORIT, 1994, p. 14; 25). 
No depoimento da biografia supracitada, a atriz Emmanuelle Laborit demonstra que seu pensamento tinha menos ordem antes da aquisição da língua, mas com certeza tinha uma espécie de lógica que a permitiu montar uma sequência, ter sensações. A ausência da língua não impede os processos cognitivos, pois a linguagem permite que o simbólico seja expresso através de gestos ou expressões, sejam elas faciais ou corporais.

O processo tardio de aquisição da língua pode distanciar o surdo do mundo que ela oferece, mas, através de gestos e ou expressões provenientes de sua linguagem, ainda que não verbal, poderá fazê-lo chegar a significados. Quando um surdo adquire uma língua tardiamente, é maior a necessidade de contextualização daquilo que se quer dizer, pois a língua escrita que obteve anteriormente à sua, nada mais é do que uma sequência que precisa decodificar. Uma língua permite generalização de conceitos, relações de significado e o domínio pleno da linguagem que inclui a língua, ordenada, gramatical. E é o que gera a possibilidade da abstração e da construção de sentidos. Esse papel de abstrair e construir sentidos e significados só pode ser desempenhado por meio da língua de sinais e pelo surdo que, após analisá-la, irá estruturar seu pensamento e conteúdos cognitivos.

De acordo com Santana (2007), o uso da língua modifica o pensamento e a língua de sinais desempenha esse papel de ampliação do cognitivo, diversificando seus processos. Se o surdo for exposto à língua de sinais desde criança, poderá internalizá-la, estruturando melhor seu pensamento e outros conteúdos cognitivos, enquanto na ausência de uma língua compreensível e estruturada, tanto a elucidação de seu pensamento quanto sua comunicação, será mais difícil.

\section{As possibilidades da língua e da linguagem}

De acordo com Chomsky (1971), todo ser humano é dotado de uma capacidade para a linguagem, independentemente de ser surdo ou ouvinte. A partir da exposição linguística que tiver, dar-se-á o desenvolvimento de sua língua natural, visto que há uma programação inata para o desenvolvimento linguístico. Com a maturação cerebral, essa capacidade linguística inata seria aguçada, permitindo assim a manifestação linguística. Experiência esta proporcionada pela exposição ao meio (tanto linguístico quanto social).

Depreende-se, dessa forma, que é impossível ensinar uma linguagem, uma vez que as condições humanas para tal tarefa já estariam pré-programadas. O mesmo raciocínio não se aplica às línguas, que apesar de terem a gramática internalizada, necessitam ser refinadas. Assim, pode-se afirmar que "a língua é uma estrutura de formas e conceitos baseada num 
sistema de regras que determinam suas interrelações arranjos e organização. Mas essas matérias-primas finitas podem se combinar para resultar num produto infinito" (CHOMSKY, 1971, p. 29). Esse produto infinito é a própria língua que, por seu uso diário, feito por falantes tão distintos, com diferentes experiências e tantas influências, torna-se cada vez mais viva.

O sociointeracionismo de Vygotsky (2000) postula que o homem modifica o ambiente e vice-versa. Essa troca está ligada ao contexto social e a aquisição da linguagem se dá a partir da interação da criança com o seu ambiente, o que lhe proporciona mais experiências.

Goldfeld (2002), a partir das ideias de Vygotsky (2000), defende que o pensamento é anterior à linguagem, a qual se desenvolverá por meio de influências externas. Um, porém, é diretamente ligado à outra, uma vez que a linguagem é vista como representação simbólica do pensamento. Mas e a língua? A língua está dentro desse contexto social em que a criança nasce. E é onde que se encontra a barreira linguística do surdo, inserido em famílias de ouvintes e falantes. Por essa particularidade, constantemente se encontra a expressão "linguagem de sinais", que deixa de lado as regras da língua. A comunicação como um todo constrói uma linguagem de fato. Se o sistema simbólico da linguagem estiver internalizado, este servirá de suporte para a língua, e o sujeito estará apto à aquisição dela, mas isso precisa ocorrer dentro do ambiente adequado à língua (de sinais, no caso dos surdos). É através da influência externa que o sujeito se constitui linguisticamente capaz de dialogar com o subjetivo.

É possível observar que, de forma distinta do inatismo, o sociointeracionismo demonstra que o cérebro é maleável e se adapta às situações. Embora não estando pronto ao nascer, recebe estímulos que o completam de forma abstrata ou simbólica. Logo, a aquisição e desenvolvimento da língua e da linguagem dependem do ambiente de exposição do sujeito, que será construído em contato com outros sujeitos - surdos ou ouvintes - de maneira a desenvolver as regras gramaticais necessárias para a construção da sua capacidade linguística e cognitiva.

\section{A aquisição linguística do surdo}

Algumas pesquisas versam sobre a aquisição linguística das línguas de sinais por surdos e a sua semelhança com a aquisição das línguas orais por pessoas ouvintes. De acordo com a teoria gerativista chomskyana, esse desenvolvimento é um fenômeno mental e surgirá do input linguístico. A aquisição da linguagem deve ocorrer o quanto antes para que o desenvolvimento do surdo não venha a ser afetado. 
Para Vygotsky (1989), a linguagem privilegia a interação social. Nesse contexto, percebe-se que o surdo tende a ter dificuldade nas relações socioculturais, devido à problemática da aquisição da linguagem, já que está exposto ao aspecto oral-auditivo de outras línguas. $\mathrm{O}$ autor ainda demonstra preocupação com o desenvolvimento das crianças e destaca:

É totalmente evidente que toda a gravidade e todas as limitações criadas pela deficiência não têm sua origem na deficiência por si mesma, mas sim nas consequências, nas complicações secundárias provocadas por esta deficiência. A surdez por si mesma poderia não ser um obstáculo tão penoso para o desenvolvimento intelectual da criança surda, mas a mudez provocada pela surdez, a falta de linguagem é um obstáculo muito grande nesta via. Por isso, é na linguagem como núcleo do problema onde se encontram todas as particularidades do desenvolvimento da criança surda. (VYGOTSKY, 1989, p. 189).

Vygotsky (1989) sugere, assim, o uso da mímica e da linguagem escrita para que o surdo consiga acessar a linguagem falada e os demais conhecimentos. E reforça que "A mímica é uma linguagem verdadeira em toda riqueza de sua importância funcional e a pronúncia oral das palavras formadas artificialmente está desprovida de sua riqueza vital e é somente uma cópia sem vida da linguagem viva" (VYGOTSKY, 1989, p. 190).

Importante mencionar que no censo do Instituto Brasileiro de Geografia e Estatística (2010) foram registrados quase 10 milhões de brasileiros com alguma deficiência auditiva. Desses, sem dados oficiais, mas mensuráveis, boa parte é de crianças surdas que nasceram em famílias ouvintes, o que prejudica não somente a iniciação linguística do surdo, mas também sua comunicação familiar, visto que a língua natural dos surdos é gestual e a da família é oral. Por isso, são necessários profissionais para dar suporte à aquisição linguística do surdo, muitas vezes já em idade escolar.

Percebe-se que os prejuízos não são somente linguísticos, mas também cognitivos e emocionais, pois não só a proficiência da língua é afetada, mas, sobretudo toda a relação e comunicação familiar. A criança surda, assim como a ouvinte, deve passar pelas etapas de desenvolvimento para que marque os processos linguísticos e cognitivos.

Não é incomum que os pais não conheçam a Libras e acabem considerando mais cômodo que o surdo se integre ao mundo ouvinte. Outros, por sua vez, acabam por desenvolver uma língua caseira para comunicação familiar. Esse tipo de comunicação priva o 
surdo das experiências linguísticas que seriam fundamentais para a construção da sua identidade como sujeito surdo. Dessa forma:

Tal como um filho de surdos-mudos, que não ouve falar à sua volta, continua mudo apesar de todos os requisitos inatos necessários ao desenvolvimento da linguagem e não desenvolve as funções mentais superiores ligadas à linguagem, assim todo o processo de aprendizagem é uma fonte de desenvolvimento que ativa numerosos processos, que não poderiam desenvolver-se por si mesmo sem a aprendizagem (VYGOTSKY; LÚRIA; LEONTIEV, 2012, p. 115).

As crianças surdas baseiam-se em suas experiências visuais e desenvolverão seu potencial linguístico a partir da exposição a informações e de input adequado. Uma criança surda, filha de pais surdos, não terá déficit na língua de sinais, já que será exposta a ela desde o nascimento. O mesmo não ocorre com surdos filhos de pais ouvintes. Como se verá na seção 5, sobre os hemisférios cerebrais, as línguas de sinais e as línguas orais têm a mesma organização e estruturação, diferenciando-se apenas por seus processos de aquisição.

De acordo com as análises de Pizzio e Quadros (2011), os bebês surdos e ouvintes passam, durante o período pré-linguístico, por duas formas de balbucio: o oral e o manual. Em determinado período, os ouvintes passam a privilegiar o oral e os surdos, o gestual. Ainda há, além do período pré-linguístico, que ocorre até os 12 meses, o estágio do primeiro sinal entre 1 e 2 anos de idade, o estágio das primeiras combinações - por volta dos dois anos e o estágio das múltiplas combinações - cerca de três anos. Passadas essas fases, por volta dos 6 anos, a criança dá início às suas primeiras produções de histórias e aos 7 anos já tem maturação suficiente da língua, associada à capacidade de emitir opiniões.

Assim, embora nem todas as crianças surdas contemplem as fases citadas, é possível considerar que um surdo exposto à língua de sinais desde sua infância será capaz de se desenvolver, linguística e cognitivamente, sem prejuízos. Através dessa exposição, o sujeito surdo também poderá formar sua identidade e reconhecer sua cultura dentro da comunidade surda.

\section{Os hemisférios cerebrais}

Estudos de Kandel, Schwartz e Jessel (1997) mostram que a linguagem é favorecida no hemisfério esquerdo do feto humano por volta da trigésima primeira semana de gestação e que as línguas naturais (de sinais ou orais) predominam, em sua maior parte, no hemisfério esquerdo. 
O hemisfério esquerdo está ligado ao pensamento e o hemisfério direito, aos aspectos visuoespaciais. Devido às interconexões entre os hemisférios, suas funções acabam por se mesclar. Há uma visão de que, nos ouvintes, a linguagem seja prevalente no hemisfério esquerdo, uma vez que o córtex auditivo também se localiza nessa região. Logo, se a área ligada à visão (visuoespacial) está no hemisfério direito, a língua de sinais, que é visuoespacial, deveria também estar aí. Porém, isso não acontece, visto que a língua de sinais tem organização semelhante à de qualquer outra língua e, por isso, também se encontra no hemisfério esquerdo.

No hemisfério direito, localiza-se o pensamento emocional não-verbal e, nas línguas de sinais, tem-se expressões faciais que permitem, tanto expressar emoções, como marcar estruturas gramaticais. Essas duas classes funcionais da língua de sinais fazem com que, no cérebro surdo que usa sinais, atuem funções apenas emocionais ou apenas linguísticas, ou seja, o hemisfério esquerdo se encarrega de expressões que são linguísticas/gramaticais, enquanto o hemisfério direito expressa os conteúdos emocionais.

Petitto et al. (2000) defendem que as línguas, mesmo de diferentes modalidades, ocorrem no hemisfério esquerdo. Caplan (2000), por sua vez, critica essa constatação pelo fato de pesquisas demonstrarem a bilateralidade do processamento das línguas de sinais. Alguns autores como Joanette et al. (1996), Fonseca e Parente (2005), Mendonça (2005) e Obler e Gjerlow (2000) afirmam que a comunicação verbal pode ser afetada em lesões do hemisfério direito, mas tais lesões não são capazes de afetar a linguagem. Por isso, nesses casos, não há afasia.

Comparando os estudos sobre esse tema, é possível inferir que os hemisférios cerebrais trabalham de forma mútua para o melhor funcionamento das línguas (tanto orais quanto gestuais), mesmo em situações de adversidade, como pôde ser observado nos casos de lesões. Também é possível observar que, nos cérebros de surdos congênitos, apenas a primeira região do lobo temporal, ligada ao estímulo sonoro, é desativada, mas o segundo nível de processamento, ligado à língua, é ativado pelos sinais emitidos que serão recebidos através de estímulos visuais.

\section{Considerações finais}

Com o intuito de conhecer mais sobre os processos de aquisição linguística dos surdos, levando em conta a visão de Vygotsky (2010), de que cognitivo e língua estão interligados, e a de Chomsky (2015), numa perspectiva biológica de relação entre língua e cognição, foi 
possível perceber e demonstrar, através dos estudos aqui descritos, que a partir da correta estimulação, o surdo apresenta o mesmo desenvolvimento linguístico do ouvinte, sem prejuízos intelectuais. Para elucidar melhor os casos específicos da língua de sinais, também foram trazidos à discussão, dentre outros autores, Piaget (1986), Quadros (1997) e Santana (2007), que tratam os temas com relevância.

Logo, foi possível observar que a aquisição linguística, tanto das línguas de sinais quanto das línguas orais, tem um processo semelhante e complexo. Além disso, evidenciouse, através das pesquisas desenvolvidas, que os surdos têm todas as capacidades orgânicas necessárias para aquisição do desenvolvimento linguístico e cognitivo. As dificuldades encontradas por eles estão relacionadas às barreiras linguísticas, muitas vezes encontradas desde a infância, no seio familiar.

Compreende-se, portanto, que a ausência de relações sociais apropriadas ao diferencial linguístico da pessoa com surdez é o que produz prejuízos não só de caráter linguístico, mas também cognitivos e emocionais e não qualquer incapacidade biológica. Quanto ao desempenho linguístico, o surdo pode se tornar amplamente fluente desde que tenha convívio social e seja exposto à experiências linguísticas com outros surdos sem privações, possibilitando assim a construção da sua própria identidade.

\begin{abstract}
This study aims to understand how the process of linguistic development of the deaf occurs in Vygotsky's perspective on the interconnection between cognition and contact with language and in the view of Chomsky, who defends the biological faculty of language. In order to do this, a bibliographic research was carried out with the intention to learn more about neural circuits, cognitive ability, innate disposition for language, and the influence of social interaction in deaf people. As studies show, deaf people are not unable to learn. They only have different possibilities and a need for adequate exposure to their mother tongue in order to better develop their linguistic potential.
\end{abstract}

Keywords: Deaf. Language. Cognition.

\title{
Referências
}

CAPLAN, David. Language related córtex in deaf individuals: functional specialization for language or perceptual plasticity. Proceedings of the National Academy of Sciences of the States of America, v. 97, n. 25, 2000, p. 13476-13477. Disponível em: https://www.pnas.org/content/97/25/13476. Acesso em: 20 jun. 2020.

CHOMSKY, Noam. Novas perspectivas linguísticas. Petrópolis: Vozes, 1971. 
Estruturas sintáticas. Trad. Gabriel de Ávila Othero e Sérgio de Moura Menuzzi. Petrópolis: Vozes, 2015.

EMMOREY, Karen. Processing a dynamics visual-spatial language: psycholinguistic studies of American sign language. Journal of Psycholinguistic Research, v. 22, issue 2, p. 153187, 1993. Disponível em: https://link.springer.com/article/10.1007/BF01067829. Acesso em: 17 jun. 2020.

FONSECA, Rochele Paz; PARENTE, Maria Alice de Mattos Pimenta. Relação entre linguagem e hemisfério direito. In: ORTIZ, Karin Zazo (Org). Distúrbios neurológicos adquiridos: linguagem e cognição. Barueri: Manole, 2005. p. 136-56

FONSECA, Vitor da. Dislexia, cognição e aprendizagem: uma abordagem neuropsicológica das dificuldades de aprendizagem da leitura. Revista Psicopedagogia, São Paulo, v. 26, n. 81, p. 339-356, 2009. Disponível em:

http://pepsic.bvsalud.org/scielo.php?script=sci_arttext\&pid=S0103-84862009000300002. Acesso em: 16 jun. 2020.

GOLDFELD, Marcia. A criança surda: linguagem e cognição numa perspectiva sóciointeracionista. 7. ed. São Paulo: Plexus, 2002.

INSTITUTO BRASILEIRO DE GEOGRAFIA E ESTATÍSTICA. Censo Demográfico 2010. Características gerais da população, religião e pessoas com deficiência. Rio de Janeiro: IBGE, 2010. Disponível em: https://biblioteca.ibge.gov.br/visualizacao/periodicos/94/cd_2010_religiao_deficiencia.pdf. Acesso em: 16 jun. 2020.

JOANETTE, Yves et al. Fundamentos neurobiológicos da recuperação das afasias: do neurobiológico ao psicossocial. In: NITRINI, Ricardo; CARAMELLI, Paulo; MANSUR, Letícia Lessa (Org.). Neuropsicologia: das bases anatômicas à reabilitação. São Paulo: Faculdade de Medicina da USP, 1996. p. 203-14

JOHNSON, Jacqueline S.; NEWPORT, Elissa Lee. Critical period effects in second language learning: the influence of maturational state on the acquisition of English as a second language. Cognitive Psychology, v. 21, issue 1, p. 60-99, 1989. Disponível em: https://www.sciencedirect.com/science/article/abs/pii/0010028589900030?via\%3Dihub. Acesso em: 16 jun. 2020.

KANDEL, Eric R.; SCHWARTZ, James H.; JESSEL, Thomas M. Fundamentos da neurociência e do comportamento. Rio de Janeiro: Guanabara Koogan, 1997.

LABORIT, Emmanuelle. O voo da gaivota. São Paulo: Best Seller, 1994.

MAYBERRY, Rachel I.; EICHEN, Ellen B. The lost-lasting advantage of learning sign language in childhood: another look at the critical period for language acquisition. Journal of Memory and Language, v. 30, issue 4, p. 486-512, 1991. Disponível em: https://www.sciencedirect.com/science/article/abs/pii/0749596X9190018F. Acesso em: 17 jun. 2020. 
MENDONÇA, Lúcia Iracema Zanotto de. Contribuições da neurologia no estudo da linguagem. In: ORTIZ, Karin Zazo (Org.). Distúrbios neurológicos adquiridos: linguagem e cognição. Barueri: Manole, 2005. p. 1-33

NEWPORT, Elissa Lee. Maturacional constraints on language learning. Cognitive Science, v. 14, n. 1, p. 11-28, 1990. Disponível em: https://onlinelibrary.wiley.com/toc/15516709/1990/14/1. Acesso em: 17 jun. 2020.

OBLER, Loraine K.; GJERLOW, Kris. Language and brain. Cambridge: Cambridge University Press, 2000.

PETITTO, Laura Ann et al. Speech-like cerebral activity in profoundly deaf people processing signed languages: Implications for the neural basis of human language. Proceedings of the National Academy of Sciences, v. 97, n. 25, p. 13961-13966, 2000. Disponível em: https://www.pnas.org/content/97/25/13961. Acesso em: 20 jun. 2020.

PIAGET, Jean. A linguagem e o pensamento da criança. Trad. Manuel Campos. São Paulo: Martins Fontes, 1986.

PIZZIO, Aline Lemos; QUADROS, Ronice Müller de. Aquisição da língua de sinais. Florianópolis: Universidade Federal de Santa Catarina, 2011. (Apostila). Disponível em: http://www.libras.ufsc.br/colecaoLetrasLibras/eixoFormacaoEspecifica/aquisicaoDeLinguaDe Sinais/assets/748/Texto_Base_Aquisi_o_de_1_nguas_de_sinais_.pdf. Acesso em: 6 fev. 2020.

QUADROS, Ronice Muller de. Educação de surdos: aquisição da linguagem. Porto Alegre: Artmed, 1997.

SANTANA, Ana Paula. Surdez e linguagem: aspectos e implicações neurolinguísticas. São Paulo: Plexus, 2007.

SKINNER, Burrhus Frederic. O comportamento verbal. Trad. Maria da Penha Villalobos. São Paulo: Cultrix/EDUSP, 1978.

VYGOTSKY, Lev Semyonovich. Fundamentos de defectologia. Havana: Pueblo Y Educación, 1989. Obras completas, tomo V.

2000

Pensamento e linguagem. Trad. Jefferson L. Camargo. São Paulo: Martins Fontes,

Aprendizagem e desenvolvimento intelectual na idade escolar. In: VYGOTSKY, Lev Semyonovich; LÚRIA, Alexander Romanovich; LEONTIEV, Alex Nikolaevich. Linguagem, desenvolvimento e aprendizagem. 12. ed. Trad. Maria da Pena Villalobos. São Paulo: Ícone, 2012. 